\title{
Interação entre salinidade e biofertilizante bovino na cultura do feijão-de-corda ${ }^{1}$
}

\author{
Francisco L. B. da Silva ${ }^{2}$, Claudivan F. de Lacerda ${ }^{3}$, G eocleber G. de Sousa ${ }^{4}$, \\ Antônia L. R. N eves ${ }^{4}$, G iovana L. da Silva ${ }^{5}$ \& Carlos H. C. Sousa ${ }^{4}$
}

\begin{abstract}
RESUMO
O bjetivou-se avaliar a interação entre salinidade e 0 uso de biofertilizante bovino sobre a condutividade elétrica do solo, crescimento inicial, trocas gasosas e teores de elementos minerais no feijão-de-corda. 0 experimento foi conduzido em ambiente protegido do Departamento de Ciências dos Solos - U FC. A semeadura foi feita em vasos, utilizando-se, como substrato, um Argissolo Vermelho Amarelo. 0 experimento obedeceu a um delineamento inteiramente casualizado, em esquema fatorial $5 \times 2$, referente a cinco níveis de sais da água de irrigação e dois de biofertilizante bovino. 0 aumento dos níveis salinos da água de irrigação inibiu o crescimento inicial das plantas, sendo menos afetado no solo com o biofertilizante. 0 aumento da salinidade da água aliado à aplicação do biofertilizante, resultou no aumento da salinidade do solo. 0 aumento do teor salino da água de irrigação provocou redução nas trocas gasosas, mas em menor proporção nas plantas desenvolvidas nos tratamentos com o biofertilizante. A extração dos elementos essenciais e de sódio obedeceu a seguinte ordem: $\mathrm{Ca}>\mathrm{K}>\mathrm{Na}>\mathrm{P}$. A aplicação de biofertilizante bovino foi eficiente ao aumentar os teores de $\mathrm{P}$ na planta e de aumentar os totais extraídos de K, P e Ca, independente no nível de salinidade aplicado. Entretanto, os efeitos benéficos da aplicação de biofertilizante bovino sobre o crescimento, trocas gasosas e extração de nutrientes, são menos expressivos nos maiores níveis de salinidade da água de irrigação.
\end{abstract}

Palavras-chave: Vigna unguiculata, salinização, irrigação, fertilizante orgânico

\section{Interaction between water salinity and bovine biofertilizer on the cowpea plants}

\begin{abstract}
The objective of this study was to evaluate the interaction between salinity levels of the water and the use of biofertilizer soil electrical conductivity of soil, initial growth, gas exchange and mineral content in cowpea plants. The experiment was performed conducted under greenhouse of the Department of Soil Science - UFC. The sowing of seeds was done in pots, using as a substrate Alfissol and tw o plants per pot. The experimental design was completely randomized in a $5 \times 2$ factorial, with 5 levels of salts and 2 levels of biofertilizer. The increase in salinity levels of irrigation water inhibited the initial grow th of the plant, being less affected in the presence of biofertilizer. The high salinity combined with application of biofertilizer caused an increase in soil salinity. Increasing salinity of irrigation water caused reduction in gas exchange, being less affected by the presence of biofertilizer. The extraction of essential elements and sodium followed the order: $\mathrm{Ca}>\mathrm{K}>\mathrm{N}$ a> $\mathrm{P}$. The application of biofertilizer was effective to increase the $\mathrm{P}$ concentration in plant and increase the total extracted $\mathrm{K}, \mathrm{Ca}$ and $\mathrm{P}$, regardless of salinity level applied. However, the beneficial effects of application of biofertilizer on growth, gas exchange and nutrient uptake, were less significant in the highest levels of irrigation water salinity.
\end{abstract}

Key words: Vigna unguiculata, salinity, irrigation, organic fertilizer

\footnotetext{
Trabalho submetido e selecionado no primeiro Simpósio Brasileiro de Salinidade realizado de 12-15/10/2010 em Fortaleza, Ceará, Brasil 1 Parte da monografia do primeiro autor apresentado ao CCA/U FC; Projeto Financiado pelo CN Pq

2 Mestrando em Engenharia Agrícola, CCA/U FC, Campus do Pici, Av. Mister Hull, 2977, CEP 60455-760, Fortaleza, CE. E-mail: leandro_custela@hotmail.com

${ }^{3}$ DENA/UFC. CEP 60455-760, Fortaleza, CE. Fone: (85) 3292-366. E-mail: cfeitosa@ufc.br

${ }^{4}$ D outorandos em Engenharia Agrícola, CCA/UFC. E-mail: sousamsa@yahoo.com.br; leilaneves7@hotmail.com; carloshens@hotmail.com

${ }^{6}$ D outoranda em Ecologia e Recursos N aturais, CCA/UFC. E-mail: gisolos@hotmail.com
} 


\section{INTRODUÇÃO}

A salinidade em áreas irrigadas é consequência, muitas vezes, do uso de água de qualidade inadequada, associado ao manejo do sistema solo-água-planta, e à deficiência do sistema de drenagem. Qualquer que seja sua fonte, a água utilizada na irrigação sempre contém sais que, em geral, variam expressivamente em qualidade e quantidade. Com relação às espécies vegetais, os efeitos da salinidade e/ou da sodicidade, são diferentes, variando entre espécies e entre genótipos de uma mesma espécie (Ayers \& Westcot, 1999).

O feijão-de-corda é uma leguminosa comestível dotada de alto conteúdo protéico, boa capacidade de fixar nitrogênio, sendo ainda pouco exigente em fertilidade do solo. Tendo como habitat as regiões de clima quente (úmida ou semiárida), é cultivado, predominantemente, nas regiões Norte e Nordeste do Brasil (Freire Filho et al., 2005). É uma espécie considerada tolerante à seca e moderadamente tolerante à salinidade, sendo que, de acordo com Ayers \& Westcot (1999), o feijão-de-corda tolera a irrigação com água salina com condutividade elétrica de até $3,3 \mathrm{dS} \mathrm{m}^{-1}$, sem redução na produtividade.

De acordo com a maioria dos autores, a salinidade reduz o crescimento das plantas em decorrência dos efeitos osmóticos, tóxicos e nutricionais (Munns, 2002). As interações iônicas que afetam a disponibilidade, absorção e transporte de nutrientes, são altamente complexas, mesmo na ausência de salinidade e de outros estresses. A salinidade adiciona um novo nível de complexidade para a nutrição mineral das culturas, afetando a atividade dos íons em solução e os processos de absorção, transporte, assimilação e distribuição (Neves et al., 2009).

Além das técnicas convencionais de adubação com base no emprego de fertilizantes minerais, um aspecto que vem sendo recentemente estudado é o emprego de formas alternativas que favorecem a aquisição de nutrientes pelas plantas em condições de salinidade, como a aplicação de biofertilizantes líquidos, o aporte de matéria orgânica e a inoculação das raízes de plantas com fungos micorrízicos. Alguns estudos têm demonstrado que o uso de biofertilizantes em ambientes salinos pode atenuar parcialmente os efeitos da salinidade sobre o crescimento das plantas (Bezerra et al., 2010; Cavalcante et al., 2010; Ould Ahmed \& Moritani, 2010). A importância do uso de biofertilizantes líquidos na forma de fermentados microbianos simples ou enriquecidos, está nos quantitativos dos elementos, na diversidade dos nutrientes minerais e na disponibilização de nutrientes pela atividade biológica (Alves et al., 2009).

O trabalho teve como objetivo avaliar os efeitos da aplicação de biofertilizante líquido bovino sobre a condutividade elétrica do solo, crescimento inicial, trocas gasosas e teores e extração de fósforo, cálcio, potássio e sódio por plantas de feijão-decorda, sob irrigação com águas de salinidade crescente.

\section{MATERIAL E MÉTOdos}

O experimento foi conduzido em ambiente protegido do Departamento de Ciências do Solo, Centro de Ciências Agrárias, Universidade Federal do Ceará, localizado no Campus do Pici, em Fortaleza ( $3^{\circ} 45^{\prime}$ S; $38^{\circ} 33^{\prime} \mathrm{W}$ ). Segundo a classificação de Köppen, a área do experimento está localizada numa região de clima Aw'. O solo utilizado como substrato foi classificado como Argissolo Vermelho Amarelo (Santos et al., 2006), coletado na camada de 0-20 $\mathrm{cm}$ de profundidade, passado em peneira de $2 \mathrm{~mm}$ de malha. Alguns atributos físicos e químicos do solo antes da aplicação dos tratamentos, estão apresentados na Tabela 1 .

Tabela 1. Atributos físicos e químicos do solo utilizado no experimento, antes da aplicação dos tratamentos

\begin{tabular}{|c|c|}
\hline Atributos químicos & Profundidade $(0-20 \mathrm{~cm})$ \\
\hline Classe textural & Franco - arenoso \\
\hline Densidade do solo $\left(\mathrm{kg} \mathrm{dm}^{-3}\right)$ & 1,40 \\
\hline $\mathrm{Ca}\left(\mathrm{cmol}_{\mathrm{c}} \mathrm{kg}^{-1}\right)$ & 0,90 \\
\hline $\mathrm{Mg}\left(\mathrm{cmol}_{\mathrm{c}} \mathrm{kg}^{-1}\right)$ & 0,90 \\
\hline $\mathrm{K}\left(\mathrm{mg} \mathrm{kg}^{-3}\right)$ & 0,08 \\
\hline $\mathrm{Na}\left(\mathrm{cmol}_{\mathrm{c}} \mathrm{kg}^{-1}\right)$ & 0,39 \\
\hline $\mathrm{H}+\mathrm{Al}\left(\mathrm{cmol}_{\mathrm{c}} \mathrm{kg}^{-1}\right)$ & 1,65 \\
\hline $\mathrm{Al}\left(\mathrm{cmol}_{\mathrm{c}} \mathrm{kg}^{-1}\right)$ & 0,05 \\
\hline PST (\%) & 10,00 \\
\hline $\mathrm{pH}\left(\mathrm{H}_{2} \mathrm{O}_{1: 2,5}\right)$ & 6,10 \\
\hline $\mathrm{CE}\left(\mathrm{dS} \mathrm{m}^{-1}\right)$ & 0,47 \\
\hline
\end{tabular}

As sementes certificadas de feijão-de-corda [Vigna unguiculata (L) Walp.], cv. EPACE 10 foram postas para germinar em vasos plásticos contendo $10 \mathrm{~kg}$ de solo; após o estabelecimento das plântulas, cinco dias após a semeadura DAS, fez-se o desbaste deixando-se as duas plantas mais vigorosas por vaso.

$\mathrm{O}$ experimento obedeceu a um delineamento inteiramente casualizado, em esquema fatorial $2 \times 5$, referente ao solo sem e com biofertilizante, irrigado com águas de salinidade 0,$8 ; 1,5$; 3,$0 ; 4,5$ e $6,0 \mathrm{dS} \mathrm{m}^{-1}$, com quatro repetições. Aplicou-se um volume de $300 \mathrm{~mL}$ do insumo, quantidade calculada com base no volume do solo e na profundidade efetiva do sistema radicular.

O biofertilizante foi preparado por meio da fermentação do esterco bovino fresco e água na proporção de 50\% (volume/ volume $=\mathrm{v} / \mathrm{v}$ ), por um período de trinta dias, em recipiente plástico, na ausência de ar. Para se obter o sistema anaeróbio a mistura foi colocada em uma bombona plástica de $200 \mathrm{~L}$ deixando-se um espaço vazio de 15 a $20 \mathrm{~cm}$ no seu interior e fechada hermeticamente. Na tampa foi adaptada uma mangueira com a outra extremidade mergulhada num recipiente com água na altura de $20 \mathrm{~cm}$, para a saída de gases (Penteado, 2007).

O preparo das soluções salinas constou dos sais de $\mathrm{NaCl}$, $\mathrm{CaCl}_{2} \cdot 2 \mathrm{H}_{2} \mathrm{O}$ e $\mathrm{MgCl}_{2} \cdot 6 \mathrm{H}_{2} \mathrm{O}$, na proporção de 7:2:1, obedecendose à relação entre $\mathrm{CEa}$ e sua concentração $\left(\mathrm{mmol}_{\mathrm{c}} \mathrm{L}^{-1}=\mathrm{CE} x \mathrm{10}\right)$ (Rhoades et al., 2000). A irrigação com as fontes de água de diferentes salinidades foi iniciada após o desbaste e a quantidade de água aplicada diariamente às plantas foi calculada de acordo com o princípio do lisímetro de drenagem (Bernardo et al., 2008), mantendo-se o solo na capacidade de campo.

Aos 45 DAS foram obtidas as seguintes variáveis: a área foliar e produção de biomassa pelas folhas e caules, que foram acondicionadas em sacos de papel e, em seguida, colocadas para secar em estufa a $60^{\circ} \mathrm{C}$, até atingirem valor constante de matéria seca. Foram obtidas a taxa fotossintética líquida, taxa de transpiração e condutância estomática em folhas 
completamente expandidas, utilizando-se um analisador de gás no infravermelho (LCi System, ADC, Hoddesdon, UK), em sistema aberto, com fluxo de ar de $300 \mathrm{~mL} \mathrm{~min}^{-1}$. As medições das trocas gasosas ocorreram sempre entre 10:00 e 11:00 h, utilizando-se fonte de radiação artificial (cerca de $1200 \mu \mathrm{mol} \mathrm{m} \mathrm{m}^{-2}$ ).

As folhas e caules, secas em estufa, foram triturados separadamente em moinho tipo Wiley, acondicionados em sacos de papel e devidamente identificados para determinação dos teores de $\mathrm{Na}, \mathrm{K}, \mathrm{Ca}$ e P. Após a obtenção do extrato nitroperclórico os teores de $\mathrm{Na}$, $\mathrm{K}$ e $\mathrm{Ca}$ foram determinados por fotometria de chama e o de P por colorimetria (Malavolta et al., 1997).

Após a coleta das plantas o solo de cada vaso foi homogeneizado e amostras foram utilizadas na determinação da condutividade elétrica do extrato solo/água $\left(\mathrm{CE}_{1: 1}\right)$.

Os resultados foram submetidos à análise de variância e de regressão e as médias comparadas pelo teste de Tukey com $\mathrm{P}<$ 0,05, utilizando-se do programa SAEG/UFV (Ribeiro Júnior, 2001).

\section{RESULTADOS E DISCUSSÃO}

\section{Condutividade elétrica do solo}

O conteúdo salino do solo aumentou significativamente com o teor salino das águas, com superioridade nos tratamentos com biofertilizante bovino (Figura 1). Esses aumentos em relação ao solo antes da aplicação dos tratamentos (Tabela 1), que eram de $0,47 \mathrm{dS} \mathrm{m}^{-1}$, se justificam em virtude de não ter sido adotada fração de lixiviação para reduzir a acumulação de sais no solo. Tendências similares foram registradas também por Garcia et al. (2008), neste tipo de solo, quando irrigado com níveis crescentes de sais na água de irrigação.

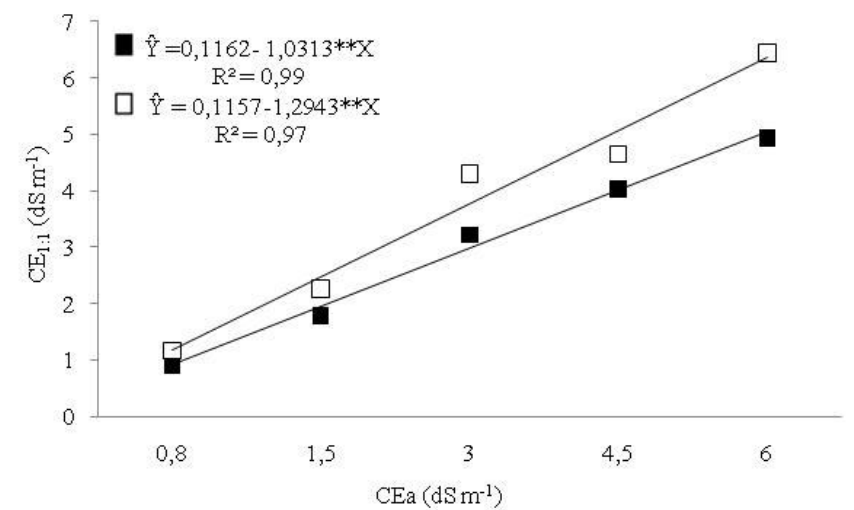

Figura 1. Condutividade elétrica do extrato de 1:1, no solo sem ( $\square$ ) e com ( $\square$ ) biofertilizante bovino

Em referência ao aumento promovido pelo biofertilizante bovino, os dados diferem de Sousa et al. (2008) ao analisarem a salinidade do substrato contendo biofertilizante bovino para formação de mudas de maracujazeiro irrigado com água salina e constataram que o aumento da salinidade da água de irrigação elevou o caráter salino dos substratos mas sempre com menor intensidade nos tratamentos com o biofertilizante e nos substratos de maior volume. Segundo os autores, o substrato com a presença do biofertilizante apresentou condutividade elétrica $12 \%$ inferior ao substrato sem o fertilizante orgânico.

\section{Crescimento e Trocas gasosas}

A matéria seca da parte aérea (MSPA), área foliar (AF), condutância estomática (gs), transpiração (A) e fotossíntese (E) foram influenciados significativamente pelos fatores salinidade e biofertilizante ( $\mathrm{p}<0,05)$, mas não se verificou a existência de interação entre eles. Os efeitos da salinidade estão em acordo com Larcher (2006), o qual se constitui um fator progressivo de distúrbios fisiológicos nas plantas e compromete o fechamento e abertura dos estômatos, além da inibir o crescimento e produção de diversas culturas.

$\mathrm{O}$ aumento da salinidade da água de irrigação inibiu o crescimento das plantas de feijão-de-corda, expresso pela área foliar (Figura 2A) e matéria seca da parte aérea (Figura 2B). A inibição do crescimento deve ter sido provocada, em maior parte, pelos efeitos tóxicos dos sais absorvidos pelas plantas, pela baixa capacidade de ajustamento osmótico da cultura e pela redução do potencial total da água provocado pelo aumento da concentração salina. Esses efeitos podem estar associados também ao nível máximo de tolerância da cultura do feijão-de-corda à salinidade do solo que de acordo com Ayers \& Westcot (1999), começa a ter seu crescimento afetado a partir de 3,3 $\mathrm{dS} \mathrm{m}^{-1}$. Tendências semelhantes foram observadas por Silva et al. (2009) em condições de casa de vegetação, e por Neves et al. (2009), na mesma cultivar de feijão-de-corda em diferentes estádios de desenvolvimento, irrigada com águas salinas em condições de campo.
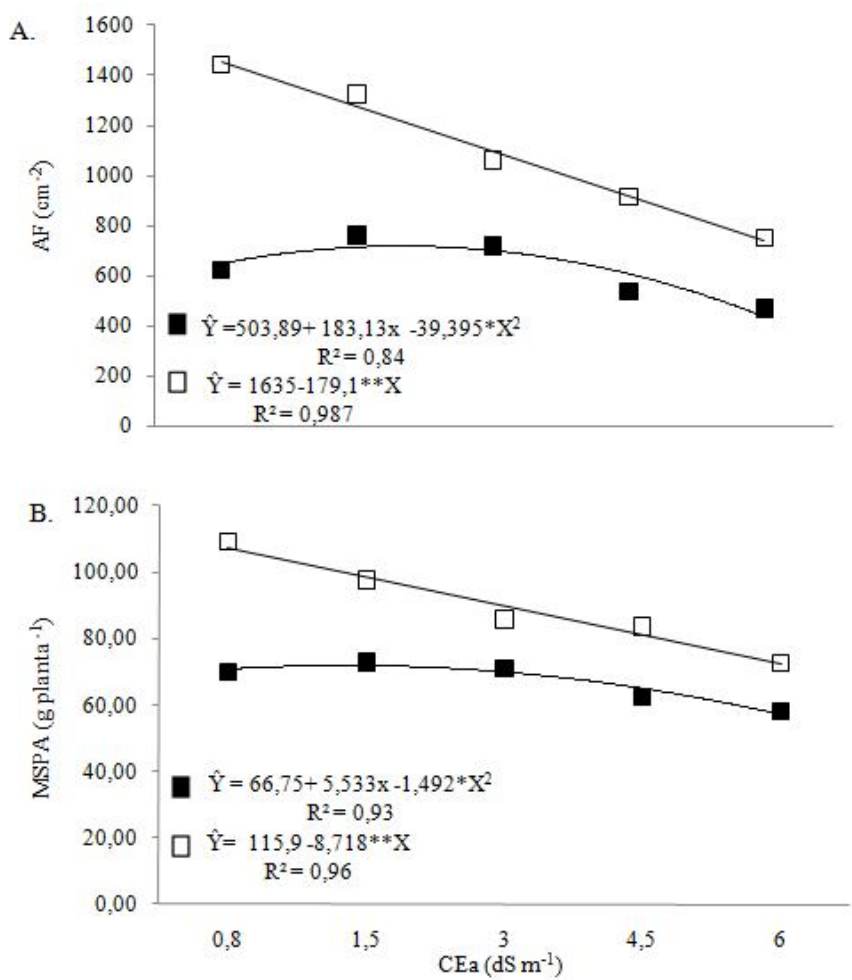

Figura 2. Área foliar (A) e matéria seca da parte aérea (B) de plantas de feijão-de-corda, irrigadas com águas sal inas no solo sem ( $\square$ ) e com ( $\square$ ) biofertilizante bovino 
Por outro lado, observa-se que, apesar do biofertilizante elevar mais o caráter salino do solo em relação aos tratamentos sem o insumo, as plantas apresentaram maior área foliar e matéria seca da parte aérea nos tratamentos com o respectivo insumo. Resultados similares, em que o biofertilizante estimulou o crescimento das plantas em ambientes salinos, foram apresentados por Nunes et al. (2009), ao avaliarem o crescimento inicial de noni (Morinda citifolia) e maracujazeiro-amarelo sob irrigação com água salina em solo sem e com biofertilizante bovino. Verifica-se, também, dentre as respectivas figuras que, apesar do biofertilizante exercer efeitos positivos no crescimento das plantas sob estresse salino, o insumo não elimina os efeitos depauperantes dos sais às plantas como concluíram Campos et al. (2009), em plantas de mamoneira (Ricinus communis).

Comportamento semelhante ao da área foliar e biomassa seca da parte aérea foi registrado também para as trocas gasosas. Constata-se, pelos resultados, que o aumento dos níveis salinos das águas de irrigação, prejudicou a atividade fotossintética, transpiração e condutância estomática das folhas das plantas (Figura 3). A redução na taxa fotossintética pode

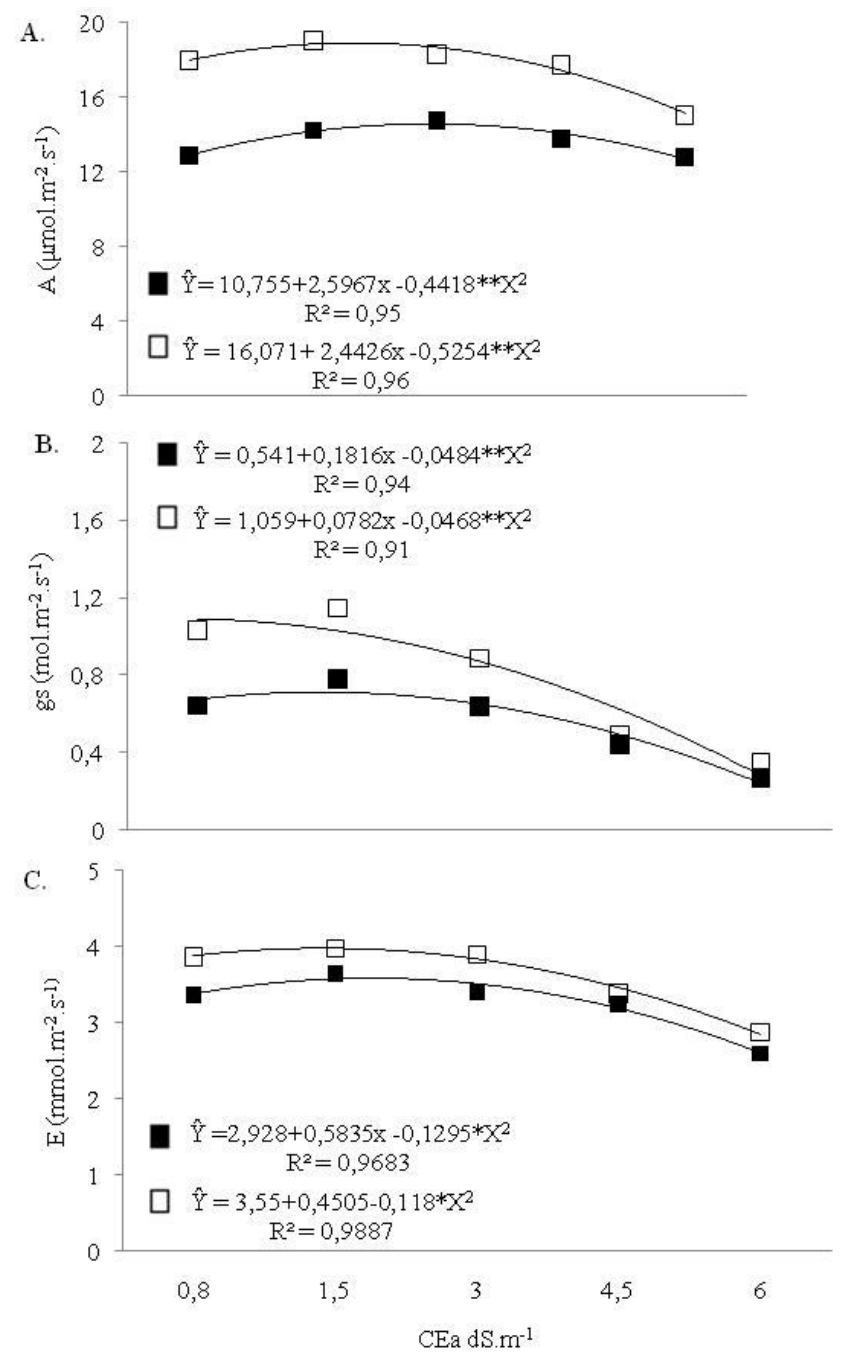

Figura 3. Valores de fotossíntese (A), condutância estomática (B) e transpiração (C) de plantas de feijão-decorda, irrigadas com águas salinas, no solo sem (ם) e com $(\square)$ biofertilizante bovino ser decorrente do fechamento estomático associado aos efeitos osmóticos e iônicos causados pela salinidade (Larcher, 2006). Dados semelhantes foram constatados por Assis Júnior et al. (2007) e Neves et al. (2009) trabalhando com a mesma cultivar de feijão-de-corda, e por Amorim et al. (2010), trabalhando com cajueiro em condições de campo.

As plantas dos tratamentos com biofertilizante bovino tiveram melhores rendimentos relacionados às trocas gasosas quando comparadas às que não receberam aplicação do insumo orgânico. A superioridade da fotossíntese, transpiração e condutância estomática, nas plantas do tratamento com biofertilizante, evidencia também a ação positiva do insumo na atenuação dos efeitos do estresse salino em feijão-de-corda, o que pode estar relacionado à melhoria na aquisição de nutrientes minerais do solo. No entanto, esses efeitos benéficos parecem decrescer nos níveis mais elevados de salinidade (Figura 3).

\section{Teores e conteúdos de elementos minerais na planta}

Os valores dos quadrados médios e da significância estatística do $\mathrm{Na}, \mathrm{K}, \mathrm{Ca}$ e $\mathrm{P}$ na folha e no caule das plantas de feijão-de-corda irrigadas com diferentes níveis de salinidade da água de irrigação $\left(0,8 ; 1,5 ; 3,0 ; 4,5 ; 5,0\right.$ e $\left.6,0 \mathrm{dS} \mathrm{m}^{-1}\right)$ na ausência e presença do biofertilizante bovino, podem ser observados na Tabela 2. Verifica-se que apesar de não haver diferença significativa na interação, os teores de Ca e $\mathrm{P}$ foram influenciados significativamente pelos fatores isoladamente $(\mathrm{p}<0,05)$ nas folhas, principal órgão da planta, em termos de avaliação nutricional. A salinidade da água de irrigação influenciou os teores de $\mathrm{Na}$ e Ca no caule, ao nível de 1 e 5\%, respectivamente, enquanto a aplicação de biofertilizante influenciou os teores de K e P nos caules (Tabela 2).

Tabela 2. Valores dos quadrados médios e da significância estatística para os teores de $\mathrm{Na}, \mathrm{K}, \mathrm{Ca}$ e P na folha e caule em plantas de feijão-de-corda irrigadas com cinco níveis de salinidade $\left(0,8 ; 1,5 ; 3,0 ; 4,5\right.$ e $\left.6,0 \mathrm{dS} \mathrm{m}^{-1}\right)$ na ausência e presença do biofertilizante bovino

\begin{tabular}{ccccrr}
\hline Elementos & Tratamento & BB & Tratamento * BB & Resíduo & CV(\%) \\
Folha \\
$\mathrm{Na}$ & $0,581^{\text {ns }}$ & $0,361^{\text {ns }}$ & $0,393^{\text {ns }}$ & 0,27 & 10,54 \\
$\mathrm{~K}$ & $1,352^{\text {ns }}$ & $3,696^{\text {ns }}$ & $1,283^{\text {ns }}$ & 0,92 & 86,01 \\
$\mathrm{Ca}$ & $0,170^{*}$ & $1,267 *$ & $0,523^{\text {ns }}$ & 0,31 & 7,15 \\
$\mathrm{P}$ & $0,836^{*}$ & $0,190^{*}$ & $0,323^{\text {ns }}$ & 0,12 & 24,90 \\
\hline \multicolumn{6}{c}{ Caule } \\
$\mathrm{Na}$ & $4,276^{* *}$ & $0,810^{\text {ns }}$ & $0,7241^{\text {ns }}$ & 13,48 & 48,13 \\
$\mathrm{~K}$ & $2,351^{\text {ns }}$ & $47,349 *$ & $14,268^{* *}$ & 4,32 & 11,33 \\
$\mathrm{Ca}$ & $0,537^{*}$ & $0,137^{\text {ns }}$ & $0,401^{*}$ & 0,81 & 11,33 \\
$\mathrm{P}$ & $0,162^{*}$ & $0,125^{*}$ & $0,3612^{\text {ns }}$ & 0,73 \\
\hline
\end{tabular}

** Significativo pelo teste $\mathrm{F}$ a $5 \%$, * Significativo pelo teste $\mathrm{F}$ a $1 \%$, $\mathrm{ns}=$ não significativo, $\mathrm{BB}=$ biofertilizante

Os níveis de salinidade da água de irrigação no solo sem biofertilizante não exerceram efeitos significativos sobre a acumulação de sódio nas folhas (Figura 4A); por outro lado, os teores do elemento aumentaram no caule (Figura 4B), situação que indica retenção desse íon nas plantas de feijão-de-corda. Dados similares foram observados por Neves et al. (2009) em condições de campo na mesma cultivar de feijão-de-corda sob estresse salino em diferentes estádios de desenvolvimento. 
O acréscimo da salinidade da água de irrigação aumentou os teores de Ca nas folhas e no caule do feijão-de-corda aos 45 DAS (Figura 4C e 4D). Resultados relacionados aos teores de $\mathrm{Ca}$ nas folhas foram semelhantes aos encontrados por Sousa et al. (2007), cultivando plantas de feijão-de-corda em condições de casa de vegetação; porém, esses autores verificaram que a salinidade influenciou de forma negativa nos teores de $\mathrm{Ca}$ nos caules. Em seus trabalhos, Garcia et al. (2007), em condições de casa de vegetação e Sousa et al. (2010) e Neves et al. (2009) em condições de campo, verificaram aumento da concentração de Ca na parte aérea de plantas de milho e feijão-de-corda, respectivamente, cultivadas em ambientes salinos. A
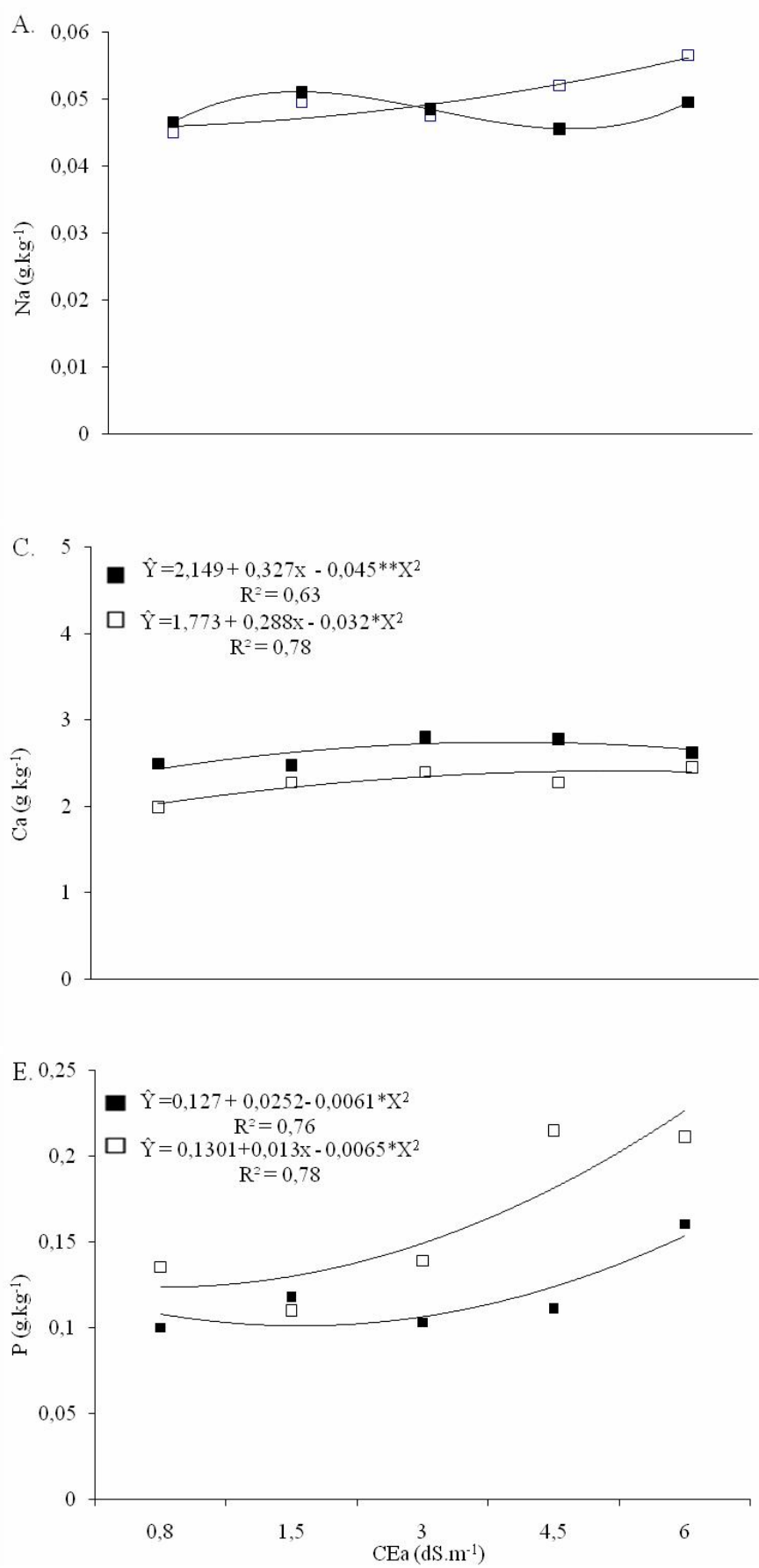

Figura 4. Teores de $\mathrm{N}$ a, $C$ a e $P$ em folhas $(A, C, E)$ e caule $(B, D, F)$ de plantas de feijão-de-corda, irrigadas com águas salinas, no solo sem ( $\square$ ) e com ( $\square$ ) biofertilizante bovino discrepância em relação aos efeitos da salinidade na aquisição de Ca pelas plantas pode estar relacionada às diferenças na composição da solução salina empregada no estudo (Sousa et al., 2007), devendo-se ressaltar que, diferente do presente estudo, na maioria dos casos se utiliza apenas o $\mathrm{NaCl}$ com agente estressor. Por outro lado, verifica-se que a presença do biofertilizante proporcionou menores teores de $\mathrm{Ca}$ nas folhas, mas não afetou os teores de nutriente nos caules.

Com relação aos teores de $\mathrm{P}$ ocorreu acréscimo nas folhas (Figuras 4E) e no caule (Figura 4F) das plantas de feijão-decorda sempre que se aumentava a concentração de sais na água de irrigação. Esses resultados estão de acordo com os de
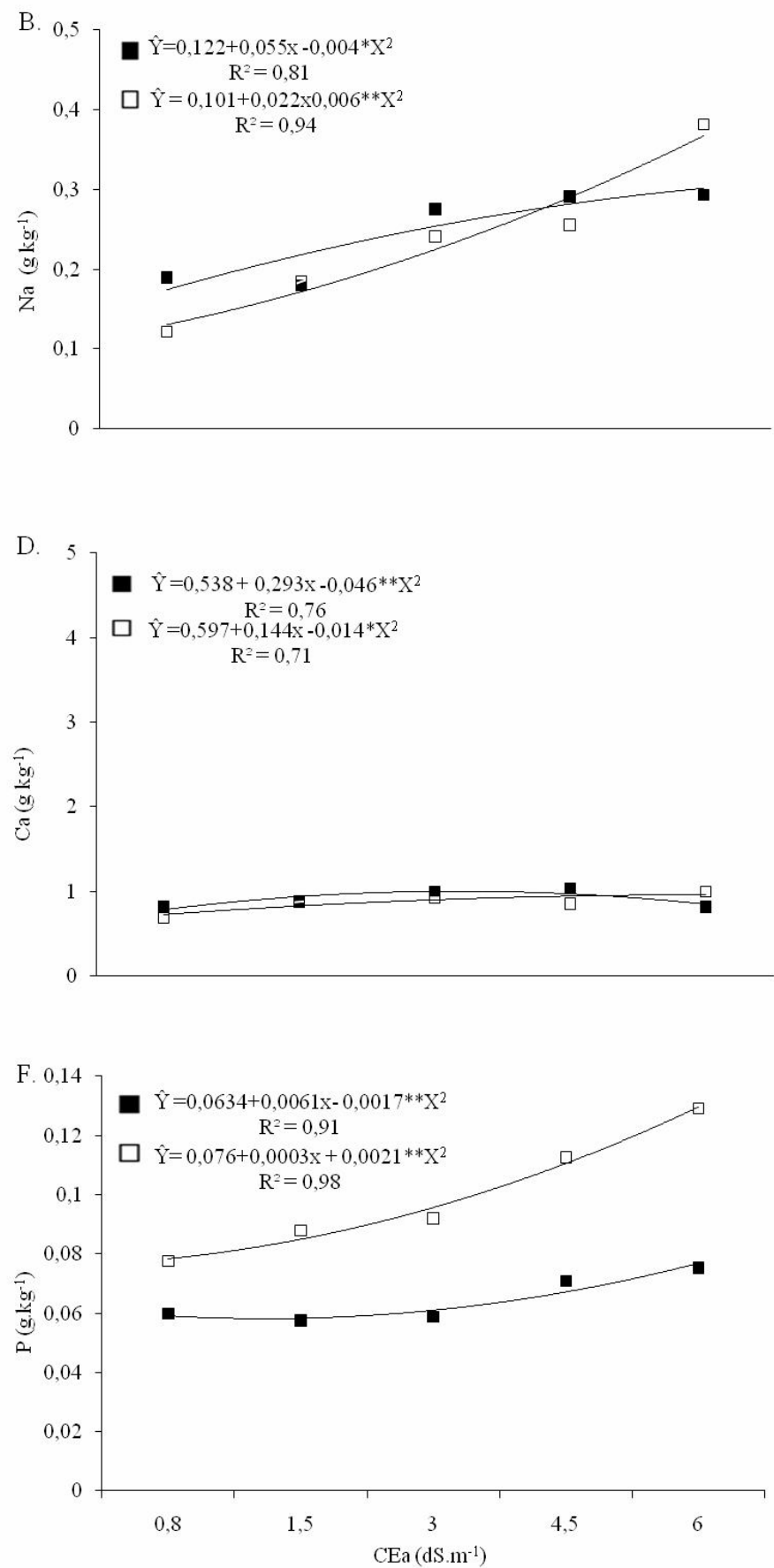
Tabela 3. Totais extraídos de $\mathrm{Na}, \mathrm{K}, \mathrm{P}$ e Ca, em g vaso-1, em plantas de feijão-de-corda irrigadas com águas salinas, no solo sem (SB) e com (CB) biofertilizante bovino

\begin{tabular}{|c|c|c|c|c|c|c|c|c|}
\hline \multirow{2}{*}{$\begin{array}{l}\text { Salinidade } \\
\text { CEa (dS m }{ }^{-1} \text { ) }\end{array}$} & \multicolumn{2}{|c|}{$\mathrm{Na}$} & \multicolumn{2}{|c|}{ K } & \multicolumn{2}{|c|}{$\mathbf{P}$} & \multicolumn{2}{|c|}{$\mathrm{Ca}$} \\
\hline & SB & CB & SB & CB & SB & CB & SB & CB \\
\hline 0,8 & $6,47^{1} \pm 0,94$ & $13,11 \pm 0,61$ & $9,07 \pm 1,3$ & $18,37 \pm 0,70$ & $0,54 \pm 0,04$ & $1,39 \pm 0,23$ & $10,68 \pm 0,83$ & $17,36 \pm 1,09$ \\
\hline 1,5 & $8,43 \pm 0,50$ & $13,21 \pm 1,33$ & $9,701,54$ & $19,52 \pm 1,91$ & $0,71 \pm 0,18$ & $1,26 \pm 0,15$ & $12,33 \pm 1,75$ & $18,39 \pm 3,08$ \\
\hline 3,0 & $7,16 \pm 0,50$ & $10,83 \pm 1,05$ & $9,86 \pm 0,60$ & $16,48 \pm 0,32$ & $0,56 \pm 0,06$ & $1,21 \pm 0,06$ & $12,22 \pm 1,03$ & $16,28 \pm 1,13$ \\
\hline 4,5 & $6,03 \pm 0,31$ & $9,32 \pm 0,56$ & $7,57 \pm 0,54$ & $14,30 \pm 0,70$ & $0,49 \pm 0,06$ & $1,55 \pm 0,08$ & $9,80 \pm 0,42$ & $14,44 \pm 1,62$ \\
\hline 6,0 & $6,68 \pm 0,47$ & $8,5 \pm 0,54$ & $7,42 \pm 0,36$ & $10,91 \pm 0,23$ & $0,65 \pm 0,06$ & $1,36 \pm 0,09$ & $9,24 \pm 0,61$ & $13,27 \pm 2,06$ \\
\hline
\end{tabular}

Lacerda et al. (2006), Sousa et al. (2007), Farias et al. (2009), em plantas de sorgo forrageiro, feijão-de-corda e gliricídia, irrigadas com águas salinas, respectivamente. Entretanto, reduções nos teores foliares de fósforo sob estresse salino foram constatados por Ferreira et al. (2007). Conforme os autores, a salinidade diminui a concentração de fósforo nos tecidos das plantas de milho, em virtude da força iônica reduzir a atividade de fosfato na solução do solo e pela diminuição da solubilidade do nutriente com o aumento da concentração de $\mathrm{NaCl}$ no ambiente radicular. Grattan \& Grieve (1999), afirmam que a interação entre a salinidade e a nutrição mineral do íon fósforo em plantas é complexa e dependente da espécie e da cultivar.

A presença de biofertilizante líquido bovino resultou em teores bem superiores de $\mathrm{P}$, em relação às plantas não supridas com esse insumo orgânico, tanto nas folhas como nos caules (Figuras 4E e 4F). Esse resultado evidencia a importância do uso de biofertilizantes líquidos na agricultura, devido especialmente à disponibilização de nutrientes às plantas (Alves et al., 2009).

A aplicação de biofertilizante líquido bovino resultou em incrementos nos totais extraídos de $\mathrm{Na}, \mathrm{K}, \mathrm{Ca}$ e P ( $\mathrm{p}<0,05)$, em todos os níveis de salinidade da água de irrigação (Tabela 3); entretanto, as maiores diferenças foram observadas nas plantas irrigadas com água de baixa salinidade. Verifica-se, por outro lado, que a salinidade da água de irrigação provocou reduções nos toais extraídos de $\mathrm{Na}, \mathrm{Ke} \mathrm{Ca}(\mathrm{p}<0,05)$, porém não afetou os totais extraídos de $\mathrm{P}(\mathrm{p}>0,05)$. A diminuição dos totais extraídos desses nutrientes em plantas sob estresse salino se deve principalmente, à inibição do crescimento provocado pelos efeitos osmóticos e tóxicos associados ao excesso de sais na zona radicular (Lacerda, 2005); comportamento semelhante foi constatado em casa vegetação, por Farias et al. (2009), na cultura do gliricídia, por Neves et al. (2009) no campo com a cultura do feijão-de-corda e por Gurgel et al. (2010), com meloeiro, em que o aumento da salinidade prejudicou a extração dos macronutrientes.

Ao comparar os tratamentos salinos, verifica-se que, de modo geral, os nutrientes foram extraídos na seguinte ordem: $\mathrm{Ca}>\mathrm{K}>$ $\mathrm{Na}>\mathrm{P}$, independentemente da adição ou não do biofertilizante ao solo (Tabela 3). Essa sequiência de extração diverge da obtida por Neves et al. (2009) em plantas da mesma cultivar de feijãode-corda, sob condições de campo, sendo observada neste caso maiores extrações de $\mathrm{K}$ em relação ao $\mathrm{Ca}$.

A redução nos totais extraídos de $\mathrm{Na}$ observados no presente estudo diverge dos resultados obtidos por Costa et al. (2008) no amaranto, em condições de casa de vegetação, por Neves et al. (2009), estudando a mesma cultivar do feijão- de-corda utilizada neste trabalho, e por Gurgel et al. (2010), em plantas de meloeiro em condições de campo. É possível que essas divergências estejam associadas às diferenças no grau de inibição do crescimento e na capacidade da planta de extrair esse elemento na zona radicular (Lacerda, 2005). É interessante ressaltar que estudos sobre a extração de nutrientes em plantas de feijão-de-corda sob estresse salino, interagindo com produtos orgânicos, são escassos.

\section{Conclusões}

1. O aumento dos níveis salinos da água de irrigação inibiu o crescimento inicial da planta, sendo menos afetado na presença do biofertilizante bovino.

2. A elevação da salinidade do solo decorrente da irrigação com água salina provocou redução na fotossíntese, transpiração e condutância estomática, sendo menos afetada com a presença do biofertilizante bovino.

3. A aplicação de biofertilizante bovino foi eficiente ao aumentar os teores de $\mathrm{P}$ na planta e de aumentar os totais extraídos de K, P e Ca, independente do nível de salinidade aplicado;

4. A extração dos elementos essenciais e de sódio obedeceu a seguinte ordem: $\mathrm{Ca}>\mathrm{K}>\mathrm{Na}>\mathrm{P}$.

5. Os efeitos benéficos da aplicação de biofertilizante bovino sobre o crescimento, trocas gasosas e extração de nutrientes, são menos expressivos nos maiores níveis de salinidade da água de irrigação.

\section{AgradeCIMENTOS}

À CAPES e ao CNPq pelo apoio financeiro.

\section{LITERATURA CITADA}

Alves, G. S.; Santos, D; Silva, J. A.; Nascimento, J. A. M; Cavalcante, L. F.; Dantas, T. A. G. Estado nutricional do pimentão cultivado em solo tratado com diferentes tipos de biofertilizantes. Revista Acta Scientiarum, v.31, , p.661-665, 2009.

Amorim, A. V; Gomes Filho, E. ; Bezerra, M. A.; Prisco, J. T.; Lacerda, C. F. Respostas fisiológicas de plantas adultas de cajueiro anão precoce à salinidade, Revista Ciência Agronômica, v.41, p.113-121, 2010. 
Assis Júnior, J. O.; Lacerda, C. F.; Silva, F. B.; Silva, F. L. B.; Bezerra, M. A.; Gheyi, H. R. Produtividade do feijão-decorda e acúmulo de sais no solo em função da fração de lixiviação e da salinidade da água de irrigação, Engenharia Agrícola, v.27, p.702-713, 2007.

Ayers, R. S.; Westcot, D. W. A qualidade da água na agricultura. Campina Grande: UFPB, 1999. 218p.

Bernardo, S.; Mantovani, E. C.; Soares, A. A. Manual de Irrigação. Viçosa, UFV, 2008. 611p.

Bezerra, M. E. J.; Lacerda, C. F.; Sousa, G. G.; Gomes, V. F. F.; Mendes Filho, P. F. Biomassa, atividade microbiana e FMA em rotação cultural milho/feijão-de-corda utilizando-se águas salinas. Revista Ciência Agronômica, v.41, p.562-570, 2010.

Campos, V. B.; Cavalcante, L. F.; Rodolfo Júnior. F.; Sousa, G. G.; Mota, J. K. Crescimento inicial da mamoneira em resposta à salinidade e biofertilizante bovino. Revista Magistra, v.21, p. 41-47, 2009.

Cavalcante, L. F.; Vieira, M. da Silva; Santos, A. F. dos; Oliveira, W. M.; Nascimento, J. A. M. do. Água salina e esterco bovino líquido na formação de mudas de goiabeira cultivar paluma. Revista Brasileira de Fruticultura, v.32, n.1, p. 251-261, 2010.

Costa, D. M. A.; Melo, N. S.; Ferreira, S. R.; Dantas, J. A. Conteúdo de $\mathrm{N}, \mathrm{P}, \mathrm{K}, \mathrm{Ca}^{2+}$ e $\mathrm{Mg}^{2+}$ no amaranto (Amaranthus spp) sob estresse salino e cobertura morta. Revista Ciência Agronômica, v.39, n.2, p.209-216, 2008.

Farias, S. G. G.; Santos, D. R.; Freire, A. L. O.; Silva, R. B. Estresse salino no crescimento inicial e nutrição mineral de gliricídia (gliricídia sepium (Jacq.) Kunth ex Steud) em solução nutritiva. Revista Brasileira de Ciência do Solo, v.33, p. 14991505, 2009.

Ferreira, P.A.; Garcia, G. O.; Neves, J. C. L.; Miranda, G V.; Santos, D. B. Produção relativa do milho e teores folheares de nitrogênio, fósforo, enxofre e cloro em função da salinidade do solo, Revista Ciência Agronômica, v.38, p.7-16, 2007.

Freire Filho, F. R.; Rocha, M. M.; Ribeiro, V. Q.; Lopez A. C. L. Feijão caupi: Avanços tecnológicos. Brasília: EMBRAPA, 2005. 519p.

Garcia, G. O.; Ferreira, P.A.; Miranda, G V.; Neves, J. C. L.; Moraes, W. B.; Santos, D. B. Teores foliares dos macronutrientes catiônicos e suas relações com sódio em plantas de milho sob estresse salino. Revista Idesia, v.25, p.93-106, 2007.

Garcia, G O.; Martins Filho, S.; Reis, E. F.; Moraes, W. B.; Nazário, A. A. Alterações químicas de dois solos irrigados com água salina. Revista Ciência Agronômica, v.39, p.7-18, 2008.

Grattan, S. R.; Grieve, C. M. Salinity-mineral relations in horticultural crops. Scientia Horticulturae, v.78, p.127-157, 1999.

Gurgel, M. T.; Gheyi, H. R.; Oliveira, F. H. T. Acúmulo de matéria seca e nutrientes em meloeiro produzido sob estresse salino e doses de potássio. Revista Ciência Agronômica, v. 41, p.18-28, 2010.

Lacerda, C. F. Interação salinidade x nutrição mineral. In: Nogueira, R. J. C.; Araújo, E. L.; Willadino, L. G.; Cavalcante, U. (ed.). Estresses ambientais: danos e benefícios em plantas. Recife: UFRPE, 2005. p.127-137.
Lacerda, C. F.; Morais, M. M. M.; Prisco, J. T.; Gomes Filho, E.; Bezerra, M. A. Interação entre salinidade e fósforo em plantas de sorgo forrageiro. Revista Ciência Agronômica, v.37, p.258263, 2006.

Larcher, W. Ecofisiologia vegetal. São Carlos: Rima Artes e Textos, 2006. 550p.

Malavolta, E.; Vitti, G. C.; Oliveira, S.A. Avaliação do estado nutricional das plantas. Piracicaba: Associação Brasileira para Pesquisa da Potassa e do Fosfato, 1997.

Munns, R. Comparative physiology of salt and water stress. Plant, Cell and Environment, v.25, p.239-250, 2002.

Neves, A. L. R.; Lacerda, C. F.; Guimarães, F. V. A.; Hernandez, F. F. F.; Silva, F. B. da.; Prisco, J. T.; Gheyi, H. R. Acumulação de biomassa e extração de nutrientes por plantas de feijãode-corda irrigadas com água salina em diferentes estádios de desenvolvimento. Revista Ciência Rural, v.39, p.758-765, 2009.

Nunes, J. C.; Cavalcante, L. F.; Rebequi, A. M.; Lima Neto, A. J.; Diniz, A. A.; Silva, J. J. M.; Brehm, M. A. S. Formação de mudas de noni sob irrigação com águas salinas e biofertilizante bovino. Revista Engenharia Ambiental, v.6, p.451-463, 2009.

Ould Ahmed, B. A.; Moritani, M. I. S. Effect of saline water irrigation and manure application on the available water content, soil salinity, and growth of wheat. Agricultural Water Management, v.97, p.165-170, 2010.

Penteado, S. R. Adubação Orgânica: Compostos orgânicos e biofertilizantes. 2.ed. Campinas: Edição do autor, 2007. 162p.

Rhoades, J. D.; Kandiah, A.; Mashali, A. M. Uso de águas salinas para produção agrícola. Campina Grande: UFPB, 2000. 117p.

Ribeiro Júnior, J. I. Análises Estatísticas no SAEG. Viçosa, UFV, 2001.301p.

Santos, H. G.; Jacome, P. K. T.; Anjos, L. H. C.; Oliveira, J. B.; Coelho, M. R.; Lumbreras, J. F.; Cunha, T. J. F. Sistema brasileiro de classificação do solo. Rio de Janeiro: Embrapa Solos, 2006. 30p.

Silva, E. N.; Silveira, J. A. G.; Fernandes, C. R. R.; Dutra, A. T. B.; Aragão, R. M. Acúmulo de íons e crescimento de pinhãomanso sob diferentes níveis de salinidade. Revista Ciência Agronômica, v.40, p.240-246, 2009.

Sousa, G. B.; Cavalcante L. F.; Cavalcante I. H. L.; Cavalcante, M. Z. B.; Nascimento J. A. Salinidade do substrato contendo biofertilizante para formacão de mudas de maracujazeiro irrigado com água salina. Revista caatinga, v.21, p.172-180, 2008.

Sousa, G. G.; Lacerda, C. F.; Cavalcante, L. F.; Guimarães, F. V. A.; Bezerra, M. E. J.; Silva, G. L. Nutrição mineral e extração de nutrientes de planta de milho irrigada com água salina. Revista Brasileira de Engenharia Agrícola e Ambiental, v.14, p.1143-1151, 2010.

Sousa, R. A.; Lacerda, C. F.; Amaro Filho, J.; Hernandez, F. F. F. Crescimento e nutrição mineral do feijão-de-corda em função da salinidade e da composição iônica da água de irrigação. Revista Brasileira de Ciências Agrárias, v.2, p.75-82, 2007. 